\title{
Expression of PIGF and sFLT-1 Biomarkers in Pregnancy Toxaemia
}

\begin{abstract}
ELENA MIHĂLCEANU ${ }^{1}$, IOANA SADYRE SCRIPCARIU ${ }^{1 *}$, IOAN TUDOR LAZĂR ${ }^{1}$, ALEXANDRA PANGAL ${ }^{1 *}$, ANA MARIA ADAM ${ }^{2}$, VIRGIL BULIMAR ${ }^{3}$, CRISTINA DANIELA DIMITRIU ${ }^{4 *}$, IRINA NEGRU ${ }^{5}$

1"Grigore T. Popa" University of Medicine and Pharmacy, Faculty of Medicine, Department mother and child, 16 Universitatii Str., 700115, Iasi, Romania

2"Dunarea de Jos" University of Galati, Faculty of Medicine and Pharmacy, 47 Domneasca Str., 800008, Galati, Romania

3"Grigore T. Popa" University of Medicine and Pharmacy,Faculty of Medicine,I-st Surgical Department,16 Universitatii Str., 700115, Iasi, Romania

4"Grigore T. Popa" University of Medicine and Pharmacy,Faculty of Medicine,Biochimistry Discipline, 16 Universitatii Str., 700115, Iasi, Romania

5"Grigore T. Popa" University of Medicine and Pharmacy,Faculty of Medicine, II-nd Surgical Department, 16 Universitatii Str., 700115, Iasi, Romania
\end{abstract}

Toxaemia is a pathological condition specific to the period of pregnancy which begins and is indissolubly related to the presence of placenta. Antiangiogenic factors, such as sFLT-1 (soluble tyrosine kinase receptor fms-like) and sEng (soluble endoglin) play an important role in the first part of pregnancy. They are linked to physiological vascular neoformation, and, in the second part of the pregnancy, grant the endothelial functionality and physiological vascular remodeling. The aim of the study is to try to establish the levels of the sFLT-1/PIGF ratio, as a prognostic tool in the patient with pre-eclampsia, depending on the influence of the cumulative risk factors. The sFLT-1 / PIGF report is a potential prognostic parameter in monitoring preeclampsia. The results of our study confirm the importance of deterring these markers for the diagnosis and monitoring of hypertensive pregnancies and at the same time to emphasize that the sFLT-1/PIGF ratio is a good predictor of preeclampsia

Keywords: pregnancy, antiangiogenic factors, toxaemia

Toxaemia is a pathological condition specific to the period of pregnancy which begins and is indissolubly related to the presence of placenta. The diseases is a multisystemic disorder, implying an increased incidence of morbidity and mortality for both the mother and the foetus[1].

This condition starts even in the absence of the foetus (as is the case of the mola hydatiforme) and the symptoms usually dissapear at the time of delivery of the placenta. Toxaemia is a condition that begins at the placenta and ends in the maternal endothelium, being characterized by generalized endothelial dysfunction and affecting all susceptible vascular vessels from kidneys, central nervous system, liver to placenta [2-4].

Antiangiogenic factors, such as sFLT-1 (soluble tyrosine kinase receptor fms-like) and sEng (soluble endoglin) play an important role in the first part of pregnancy. They are linked to physiological vascular neoformation, and, in the second part of the pregnancy, grant the endothelial functionality and physiological vascular remodeling. Soluble FLT-1 is a circulating anti-angiogenic protein that binds to the receptor of the PIGF and VEGF, thus preventing interaction with endothelial receptors, causing endothelial dysfunction. Endoglin is a surface co-receptor protein of TGF (transformig growth factor) $\beta 1$ and $\beta 3$ [5].

The sEng factor is its soluble form, a novel anti-angiogenic factor that acts in synergy with sFLT-1. In normal pregnancy, a proangiogenic status appears, with low levels of sFLT-1 and increased levels of PIGF, by the end of the second trimester. Towards the end of the pregnancy these levels return to normal. In pregnant women with toxaemia, angiogenic profile abnormalities appear, with early changes in the prevalence of anti-angiogenic status leading to endothelial dysfunction. Thus PIGF and VEGF levels are lower than normal, and sFLT-1 and sEng levels are increased. sFLT-1 released from the placental circulation in large quantities will destroy the homeostasis of the maternal endothelium, resulting in hypertension, proteinuria and other systemic manifestations of preeclampsia.

Also, the sFLT-1 factor is an antagonist of VEGF (Vascular Endothelial Growth Factor) on endothelial cells in kidney, brain and liver vessels. Some researchers have confirmed that the increased circulating level of the sFLT-1 factor predicts the onset of preeclampsia and is correlated with the severity of the disease. However, not all patients with toxaemia had

*email:ioana.scripcariu@umfiasi.ro; alexandra.pangal@umfiasi.ro; cristina.dimitriu@umfiasi.ro 
altered levels of sFLT-1 (the soluble tyrosine kinase receptor fins-like) and PIGF (placental growth factor). It is not yet clear whether patients with toxaemia and low levels of sFLT-1 somehow do not have a nonangiogenic alternative form of the disease [5-7].

Considering the importance of careful maternal-fetal monitoring and therapeutic intervention at the right / optimal time in pre-eclampsia, to avoid fetal and maternal complications, this study evaluated the sensitivity and specificity of both usual and complex laboratory tests, which aims to evaluate some markers of angiogenesis, in the diagnosis and management of toxaemia

The aim of the study is to try to establish the levels of the sFLT-1 /PIGF ratio, as a prognostic tool in the patient with pre-eclampsia, depending on the influence of the cumulative risk factors.

\section{Experimental part}

\section{Material and method}

This research was applied on a study group of 138 pregnant women, between 2012 and 2018 in the "Cuza Voda" Maternity Iasi, who gave their free consent to enter the study, for which the PIGF and sFlt biomarkers were determined and the sFLT-1 / PIGF ratio was calculated.

The hematological and biochemical determinations were performed in the "Cuza Voda" Maternity Medical Analysis laboratory in Iasi, and the immunological ones in the specialized ambulatory of the "Sf. Spiridon" University Hospital in Iasi.

For hematological determinations, blood was collected on K3EDTA-type anticoagulant and using an automatic hematology analyzer (Celltac MEK-6318 K). Biochemical determinations used serum obtained after blood collection in "activator clot" tubes and centrifugation at $4000 \mathrm{rpm}, 10$ minutes.

An automatic Chemistry Analyzer, RX Imola model with the use of calibrators and control sera was used to determine the biochemical parameters.

Data were uploaded and processed using the statistical functions of SPSS 13, at the 95\% significance threshold (p $<0.05)$. The statistical analysis used significance tests ANOVA, F test.

\section{Results and discussions}

\section{$P I G F$}

In the pre-eclampsia group, the individual values of PIGF recorded a variation in the range 16.37-942 $\mathrm{pg} / \mathrm{mL}$, with a significantly lower mean value $(119.3 \mathrm{pg} / \mathrm{mL})$ compared to the average value recorded in the control group (327, 57 $\mathrm{pg} / \mathrm{mL})$ or in the patients with high blood pressure- HBP - $(129.13 \mathrm{pg} / \mathrm{mL})(\mathrm{p}=0.003)$ (Figure 1$)$.

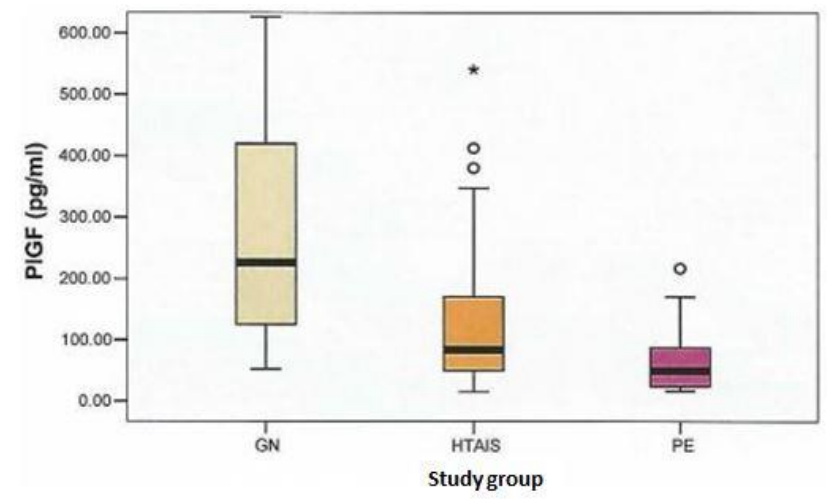

Fig. 1. Average PIGF

values for study groups

Related to the age group, the mean PIGF values did not reveal statistically significant differences $(\mathrm{p}=0.704)$, although it is observed that patients under the age of 20 years have a median PIGF of approximately $200 \mathrm{pg} / \mathrm{mL}$, and at age between 20 and 34 years the median exceeds the value of $100 \mathrm{pg} / \mathrm{mL}$ and at the age of over 35 years the median is within normal limits.

The correlations between the individual PIGF values and the maximum recorded blood pressure values were indirect, moderate in intensity. Higher PIGF values were accompanied by low systolic $(r=-0.359 ; R 2=0.1771, p=0.001)$ or diastolic $(\mathrm{r}=-0.320 ; \mathrm{R} 2=0.1331, \mathrm{p}=0.003)$ (Figures 2 and 3$)$. 

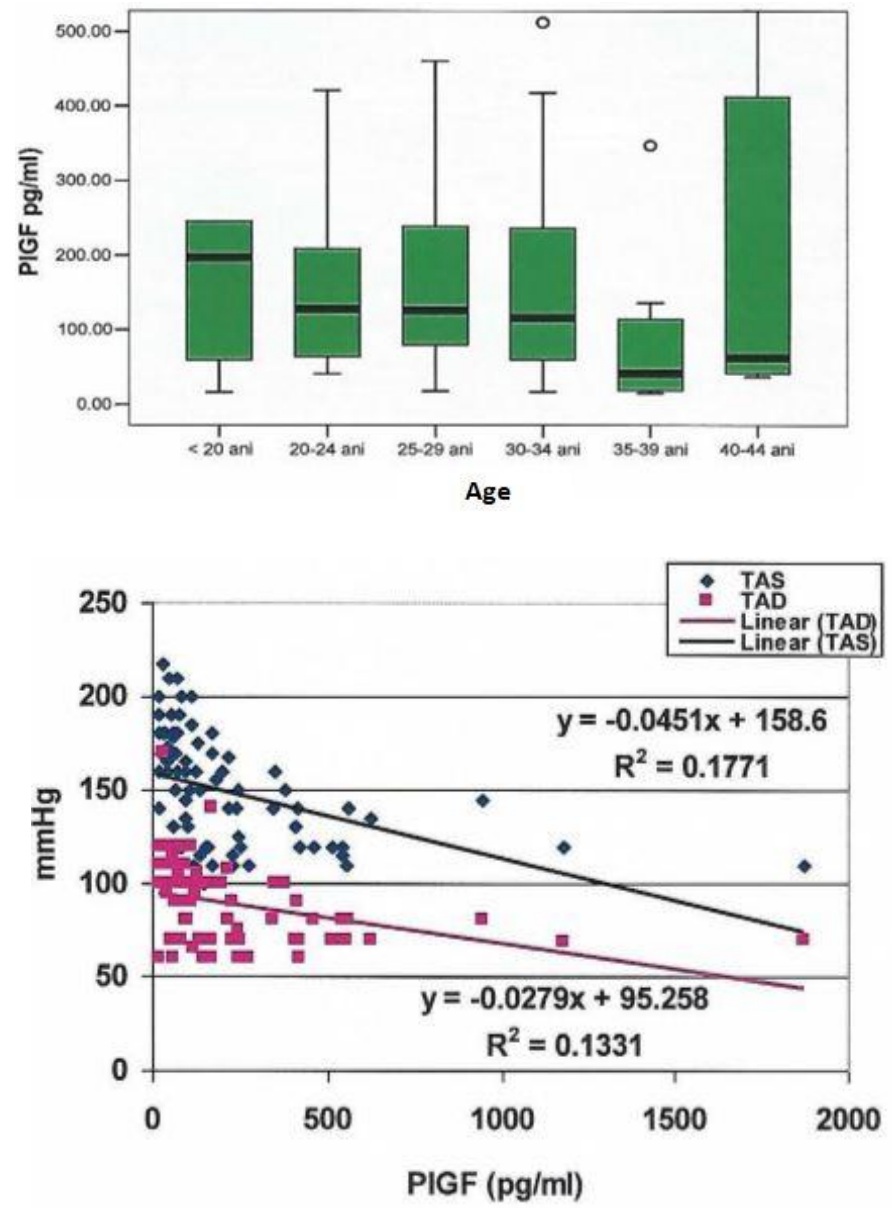

Fig. 2. Average PIGF values by age group

Fig. 3. Correlation of individual PIGF values and maximum blood pressure recorded

sFLT-1

sFLT-1 ranged from 1152 to 32708 , with one variant over $92 \%$, registering in the patients with toxaemia the highest mean value $(14365 \pm 6464)$, significantly higher compared to the other study groups $(p=0.001)$.

In pregnant women with toxaemia, s-Flt ranged from 1804 to $27303 \mathrm{pg} / \mathrm{mL}$, recording an average value of 14365 $\mathrm{pg} / \mathrm{ml}$.

For pregnant women with HBP, the individual values recorded a wide variation in the range $1552-32708 \mathrm{pg} / \mathrm{mL}$, with an average of the lot of $9892 \mathrm{pg} / \mathrm{mL}$.

The individual values of sFLT-1 recorded in normal pregnancies varied in the range $152-6144 \mathrm{pg} / \mathrm{mL}$, with an average value of $3278 \mathrm{pg} / \mathrm{mL}$ (Figure 4).

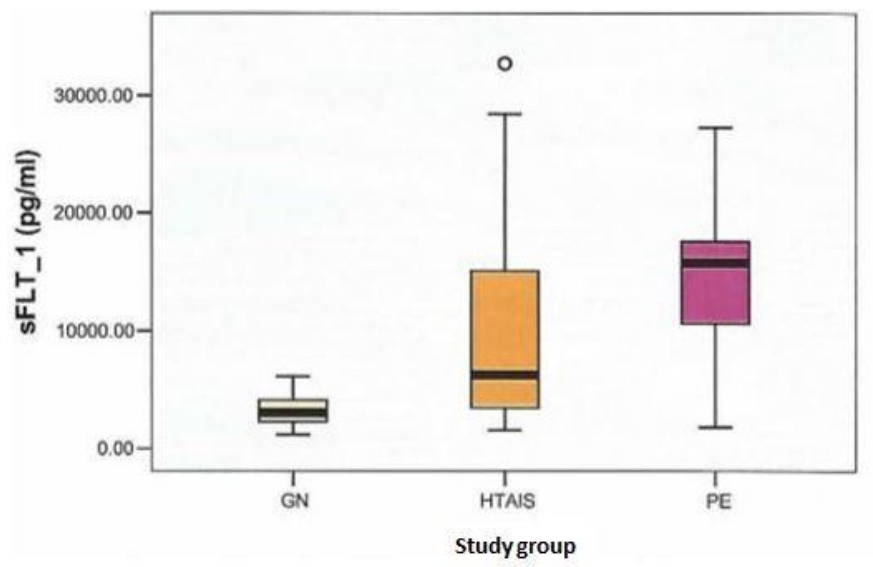

Fig.4. Average values of SFLT-1 by study groups

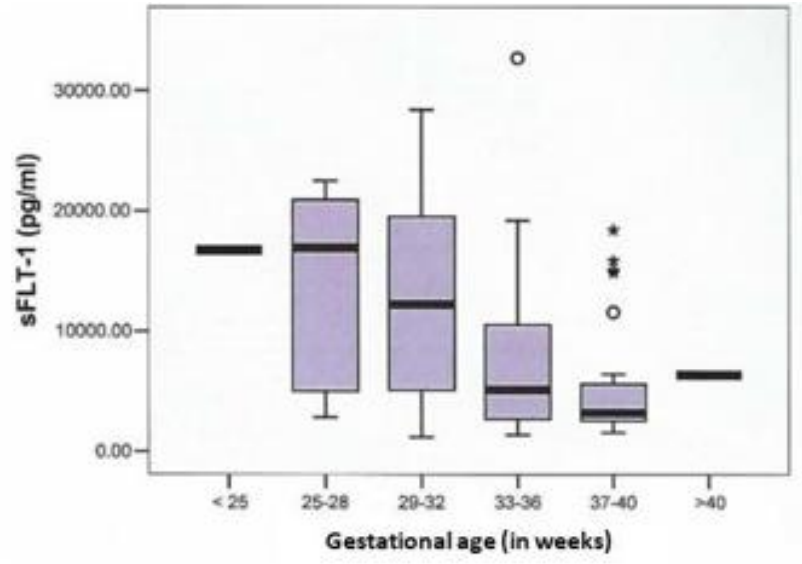

Fig. 5. Mean values of sFLT-1 in according to gestational age 
Depending on the gestational age, the mean value of sFLT-1 was significantly higher. In gestational weeks 25-28 $(13867 \mathrm{pg} / \mathrm{mL}) \sim 29-32(13033 \mathrm{pg} / \mathrm{mL})(\mathrm{p}=0.001)$ (Figure 5).

The correlations between the individual values of sFLT-1 with the values of the maximum blood pressure recorded were direct, moderate in intensity, but statistically significant. Higher values of sFLT-1 were accompanied by increased values of systolic $(r=+0.397 ; \mathrm{R} 2=0.3445, \mathrm{p}=0.001)$ or diastolic $(\mathrm{r}=+0.430 ; \mathrm{R} 2=0.2755, \mathrm{p}=0.001)$.

\section{Ratio sFLT-1 /PIGF}

The values of the sFLT-1/PIGF report showed the following variations $(\mathrm{p}=0.001)$ :

-in the PE group, the range of values varies between $1.92-1124.56$ and has the highest average value (417.62 \pm 350.73 ), especially at a gestational age of $37-40$ weeks (about $600 \pm 200$ );

-in the group of patients with HTA, the ratio ranges from 2.87 to 1309.18, with an average to the group of $199.09 \pm$ 186.14 ;

-in the control group, the sFLT-1 / PIGF ratio ranged from 0.88 to 110.64 , beingrecorded the lowest mean value (23.70 \pm 17.02 ) (Figure 6).

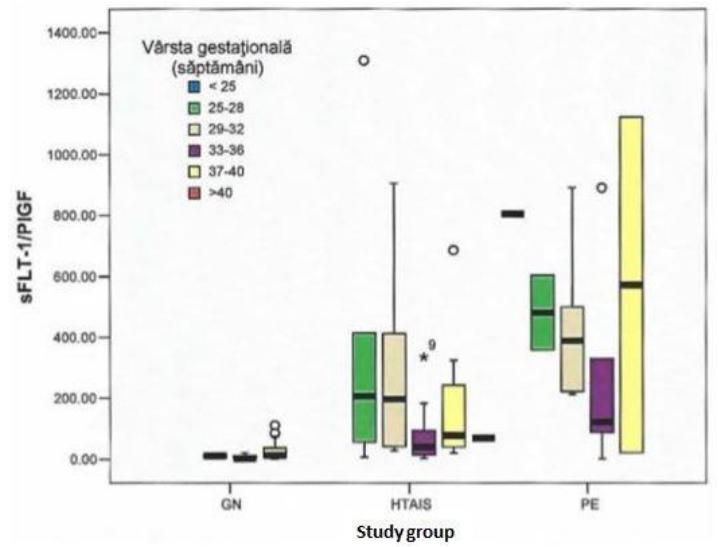

Fig. 6. Average values of the sFLT-1/PIGF report on study groups according to gestational age

In patients with toxaemia, there is a direct correlation, moderate in intensity, between systolic blood pressure (TAS) and sFLT-1 / PIGF ( $\mathrm{r}=+0.555 ; \mathrm{p}=0.026)$, but the values of increased diastolic blood pressure (TAD) are associated with elevated sFLT-1 /PIGF levels in only $18.5 \%$ of patients $(r=+0.185 ; p=0.493)$.

In pregnant women in the HTAIS group, the correlations between TAS $(r=+0.014 ; p=0.937)$ and TAD $(r=+0.105 ; p$ $=0.555)$ with the sFLT-1 / PIGF ratio were not statistically significant (Figure 7).
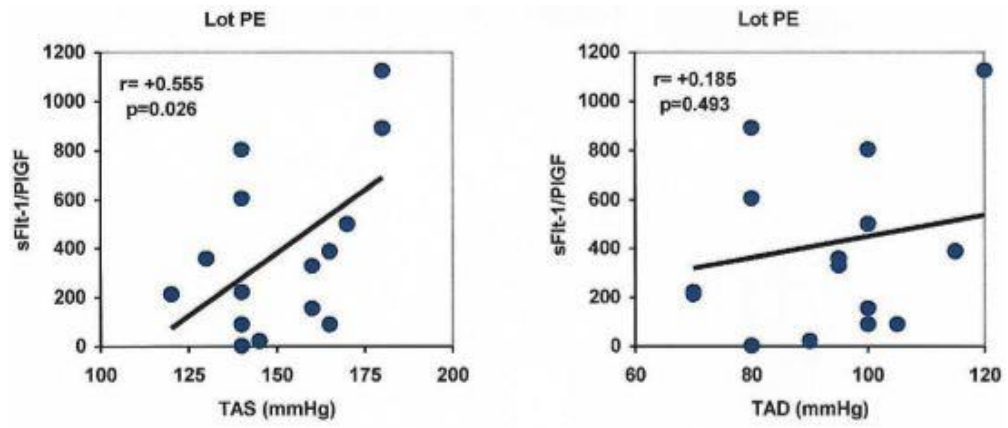

Fig. 7. Correlation of sFLT-1 / PlGF ratio with blood pressure
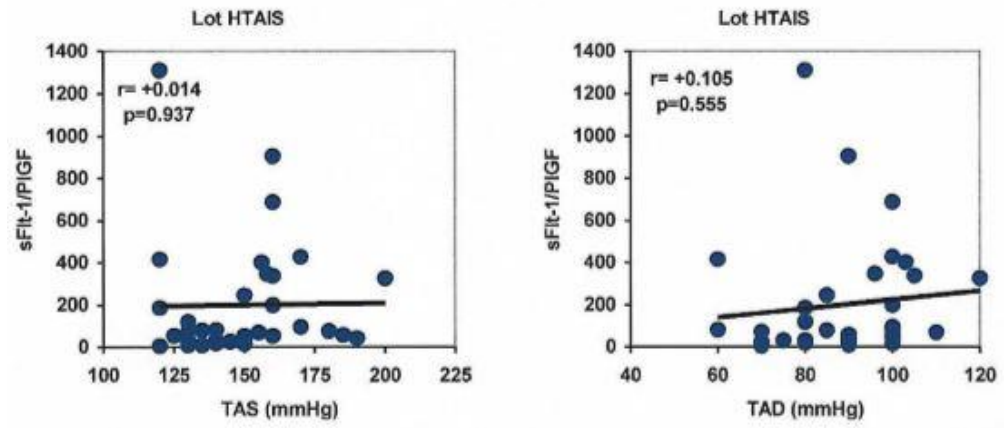

REV.CHIM.(Bucharest) $\bullet 71 \diamond$ no. $1 \diamond 2020$ 
In patients with toxaemia, TGO is significantly correlated, with a direct correlation of moderate intensity with sFLT-1 $(\mathrm{r}=+0.535 ; \mathrm{p}=0.033)$, but with PIGF $(\mathrm{r}=-0.070 ; \mathrm{p}=0.796)$ or the sFLT-1 /PIGF ratio $(\mathrm{r}=-0.031 ; \mathrm{p}=0.909)$ the indirect correlations were not statistically significant (Figure 8).

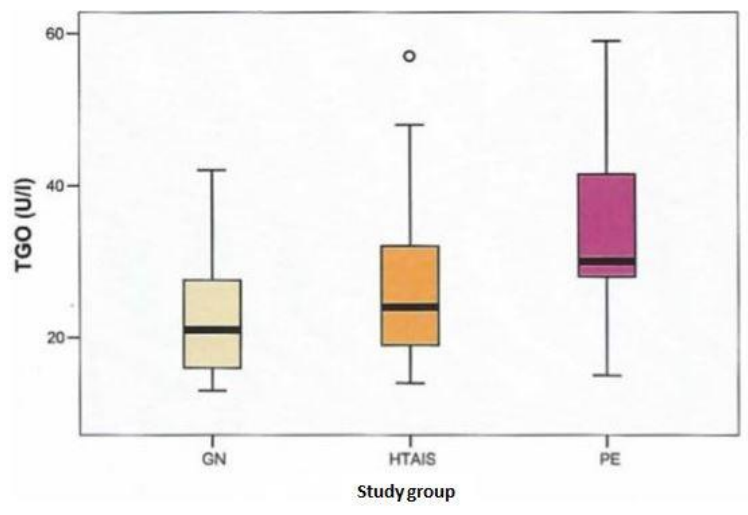

Fig. 8. Average values of TGO on study groups

In patients with toxaemia, TGP is significantly correlated, with moderate intensity direct correlation with sFLT-1 ( $\mathrm{r}=$ $+0.532 ; \mathrm{p}=0.034)$, but with P1GF $(\mathrm{r}=-0.066 ; \mathrm{p}=0.808)$ or the sFLT-1 / PIGF ratio $(\mathrm{r}=-0.026 ; \mathrm{p}=0.925)$ the indirect correlations were not statistically significant (Figure 9).

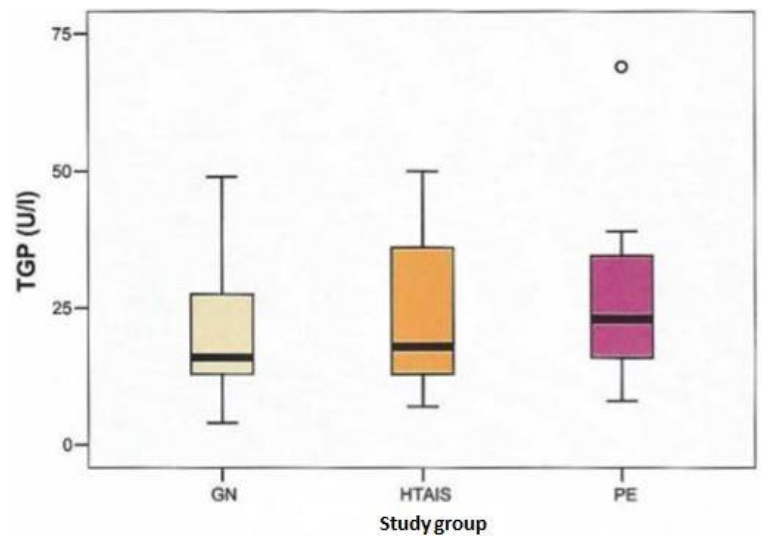

Fig. 9. Average values of TGP on study groups

Increased urine protein levels correlate with increased sFLT-1 /PIGF ratio in $44.8 \%$ of PE patients $(\mathrm{r}=+0.448 ; \mathrm{p}=$ $0.049)$ and $32.5 \%$ of patients with HTA $(r=+0.325 ; \mathrm{p}=0.060)$.

In the case study, it is noted that preeclampsia was characterized by increased levels of sFLT-1, associated with hypertension, proteinuria and increased CRP values (Figure 10).
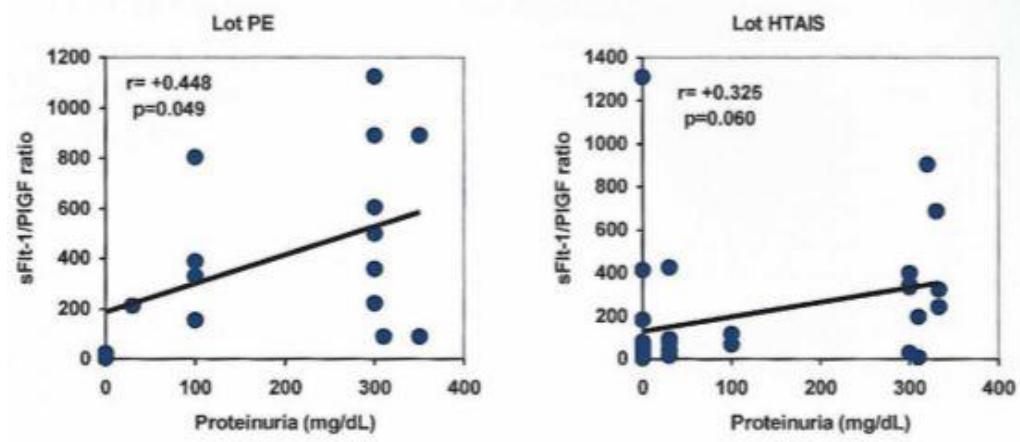

Fig. 10. Correlation of sFLT-1 / PlGF ratio with proteinuria

It should be noted that the sFLT-1 /PIGF ratio is the best predictor of toxaemia - with an accuracy of 72.3\%, but sFLT1 is a good predictor as the accuracy reaches a level of $61.6 \%$, an aspect that it is not confirmed by the accuracy of PIGF (30.8\%) (Figure 11). 


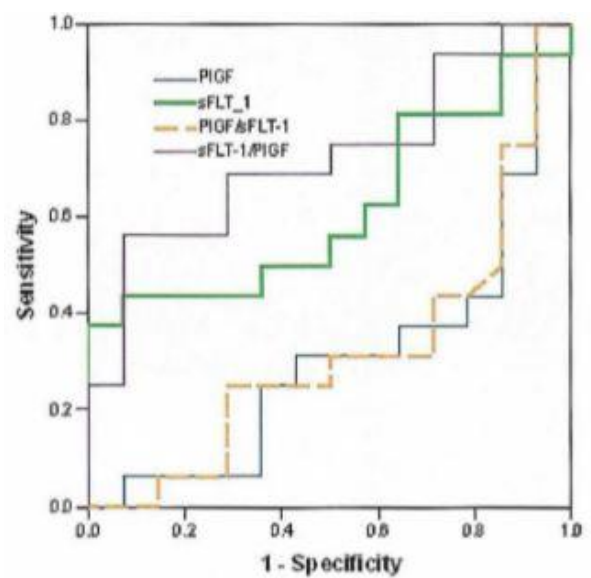

Fig. 11. ROC curve - optimal values for angiogenic analyzes

Toxaemia, this systemic vascular disease, can affect many organs, causing severe complications for both the fetus and mother. Although the exact causes leading to the onset of preeclampsia are not known, however, it has been found that placental dysfunction plays an important role in its occurrence, correlating with subsequent maternal endothelial dysfunction [8-10].

Following examination of the placenta in pregnant women with severe toxaemia, the presence of infarcts, fibrinous necrosis of the walls of the blood vessels, thrombosis and signs of chronic inflammation were frequently found [11, 12].

In toxaemia, the cytotrophoblastic invasion is incomplete, the cytotrophoblastic cells being present only in the superficial layers of the uterine endometrium $[11,13]$. Therefore, vascular resistance will increase significantly, as the spiral arteries of the endometrium fail to be properly remodeled [14].

Alternatively, pregnant women with old vascular diseases may develop signs and symptoms of the toxaemia, even if sFLT-1 values are low. The renin-angiotensin-aldosterone system is also affected in toxaemia. Unlike normal pregnancies, whose vascular response decreases in the presence of vasoactive peptides, such as angiotensin II and epinephrine, in pregnant women who develop preeclampsia, the vascular response is much too strong (Ill). [5, 7, 15].

There are studies in which agonist antibodies have been identified on angiotensin II receptors. This type of antibody was subsequently injected into pregnant female mice, and these developed hypertension, proteinuria, and increased levels of sFLT-1 and sEng [16 - 20].

Renal changes in toxaemia are explained by a particular glomerular lesion characterized by endothelial proliferation of the capillaries. Thus, in toxaemia, urea and creatinine may have approximately equal or slightly increased values compared to normal pregnancy, but the degree of proteinuria varies widely between minimal and nephrotic values $[5,11$, 21].

The hepatic impairment in toxaemia depends on the severity of the disease, generally the values of transaminases and lactate dehydrogenase, being moderately increased, except for the installation of HELLP syndrome, when their values are much increased [7, 22].

Indeed, increased levels of transaminases are a clinical marker of severity. Liver rhinoscopic examination may reveal periportal hemorrhage, ischemic injury, and fibrin deposits (193). In this study, the determination of TGO constituted a test with a sensitivity $(\mathrm{Se})$ higher than the specificity $(\mathrm{Sp})$ for TGO values of $275 \mathrm{IUIL}(\mathrm{Se}=0.812 ; \mathrm{Sp}=0.665)$.

Disorders in these balance factors can lead to aberrant placental vascular development. Their release into the maternal circulation contributes to the adaptation of the maternal cardiovascular system to pregnancy. Many issues in this field such as assay methodology and lack of data considering different placental cell types mean that the physiological roles of these factors in the maternal and placental circulations are making them a misnomer [23].

Motivated by the fact that the plasma level of pro- and anti-angiogenic factors changes a few weeks before the clinical onset of preeclampsia, they represent a promise in the early diagnosis of the disease. In normal pregnancy PIGF increases in the first 2 trimesters and decreases thereafter, as the pregnancy reaches its term; sFLT-1 is stable in the first and second trimesters, then increases steadily until term, explaining the role of this protein in "interrupting" the pregnancy.

PIGF and sFLT were harvested in the study group in the third trimester, before birth and correlated with clinical signs, biological evidence and risk factors.

The results obtained in this study indicated a significant increase in the serum concentration of the antiangiogenic factor sFLT-1 more than 4 times for the PE group and over 3 times for the HTA group compared to the control group. The average values obtained for the PIGF parameter showed a decrease of more than 2.5 times in both the PE group and the HTA group compared to the control group. On the other hand, the results obtained for the studied groups showed that the sFLT-1 / PIGF ratio represents a good predictor of preeclampsia. 
In the case study, summarizing the parameters that may be risk factors to develop preeclampsia, the following aspects are highlighted:

-The mean age in patients with preeclampsia was approximately 29 years $(\mathrm{p}=0.001)$.

-The monitoring of the weight status showed a significant weight increase during pregnancy in PE pregnant women $(32 \%$ vs $18 \%)(\mathrm{p}=0.002)$.

-Mean blood pressure shows significant diastolic cardiac dysfunction

-higher in the group of patients at risk of preeclampsia $(\mathrm{p}=0.001)$.

-The management and the parity did not reveal significant differences between the groups monitored ( $p>0.05)$.

-The values of biological markers, in general, did not show significant differences.

-However, the significantly higher mean values of TGO, uric acid, serum urea and proteinuria in the pre-eclampsia group of pregnant women should be highlighted.

-Reactive protein $C$ recorded significantly higher mean values in PE pregnant women $(p=0.001)$.

These two biomarkers are also used as a screening tool for small-for-gestational age pregnancies, but there is not a clear cut-off value to use for this. More research is needed in the field of these biomarkers in order to differentiate growth restriction on their own and how these biomarkers could be used in toxaemia evaluation risk. Moreover relevant clinical and ultrasound facts could add important information in clinical routine diagnostics and prevention of toxaemia, using specific biomarkers [24].

\section{Conclusions}

PIGF and sFLT-1 / PIGF ratio correlate with clinical and laboratory signs of the cases studied. The higher sFLT-1 / PIGF ratio can evaluate the risk of preterm birth. The sFLT-1 / PIGF report is a potential prognostic parameter in monitoring preeclampsia. The results of our study confirm the importance of deterring these markers for the diagnosis and monitoring of hypertensive pregnancies and at the same time to emphasize that the sFLT-1/PIGF ratio is a good predictor of preeclampsia. In conclusion, similar to what appears in other medical fields, the use of new technologies in preeclampsia, seems quite promising. Although the number of studies is still insufficient, they suggest that the aberrant profile described by transcriptomics, proteomics, and metabolomics may be predictive of the disease, opening a new pathway in the discovery of biomarkers for preeclampsia. Further studies are needed to clarify the potential role of PIGF as well as sFlt in the diagnosis and algorithm of preeclampsia.

\section{Referrences}

1.SIBAI B, DEKKER G, KUPFERMINC M. Pre-eclampsia. Lancet. 2005; 4;365(9461):785-99.

2.KARUMANCHI SA, BDOLAH Y. Hypoxia and sFlt-1 in preeclampsia: the "chicken-and-egg" question. Endocrinology. 2004;145(11):4835-7.

3.CHAMES MC, LIVINGSTON JC, IVESTER TS, BARTON JR, SIBAI BM. Late postpartum eclampsia: a preventable disease? Am J Obstet Gynecol. 2002;186(6):1174-7.

4.AHMED A, DUNK C, AHMAD S, KHALIQ A. Regulation of placental vascular endothelial growth factor (VEGF) and placenta growth factor (PIGF) and soluble Flt-1 by oxygen--a review. Placenta. 2000;21 Suppl A:S16-24.

5.KLEINROUWELER CE, WIEGERINCK MM, RIS-STALPERS C, BOSSUYT PM, VAN DER POST JA, VON DADELSZEN P, MOL BW, PAJKRT E; EBM CONNECT Collaboration. Accuracy of circulating placental growth factor, vascular endothelial growth factor, soluble fms-like tyrosine kinase 1 and soluble endoglin in the prediction of pre-eclampsia: a systematic review and meta-analysis. BJOG. 2012;119(7):778-87.

6.LEVINE RJ, MAYNARD SE, QIAN C, LIM KH, ENGLAND LJ, YU KF, Schisterman EF, Thadhani R, Sachs BP, Epstein FH, Sibai BM, Sukhatme VP, Karumanchi SA. Circulating angiogenic factors and the risk of preeclampsia. N Engl J Med. 2004;350(7):672-83.

7.SIBAI BM, COPPAGE KH. Diagnosis and management of women with stroke during pregnancy/postpartum. Clin Perinatol. 2004;31(4):853-68, viii.

8.MATSUO K, KOOSHESH S, DINC M, SUN CC, KIMURA T, BASCHAT AA. Late postpartum eclampsia: report of two cases managed by uterine curettage and review of the literature. Am J Perinatol. 2007;24(4):257-66.

9.HÎNGANU D, EVA I, STAN C, HÎNGANU MV. Morphological aspects of the rectal neovascularization in colorectal cancer - anatomical-surgical and imaging implications. Rom J MorpholEmbryol 2016; 57(1): 161-165

10.TOMA AG, SALAHORU P, HINGANU MV, HINGANU D,DIMA-COZMA LL, PATRASCU A, GRIGORESCU C. Reducing the Duration and Improving Hospitalisation Time by Using New Surgical Tehniques and Psychotherapy. Rev Chim (Bucharest), 70, no. 1, 2019, p.143-146.

11.YOUNG BC, LEVINE RJ, KARUMANCHI SA. Pathogenesis of Preeclampsia. Annual review of pathology-mechanisms of disease Book Series: Annual Review of Pathology-Mechanisms of Disease 2010; 5:173-192

12.SAFTLAS AF, LEVINE RJ, KLEBANOFF MA et al. Abortion, changed paternity, and risk of preeclampsia in nulliparous women. Am J Epidemiol 2003; 157;(12): 1108-1114.

13.ZHOU Y, DAMSKY CH, CHIU K, ROBERTS JM, Fisher SJ. Preeclampsia is associated with abnormal expression of adhesion molecules by invasive cytotrophoblasts. J Clin Invest 1993; 91(3): 950-960.

14.NILSSON E, SALONEN ROS H, Cnattingius S, Lichtenstein P. The importance of genetic and environmental effects for pre-eclampsia and gestational hypertension: a family study. BJOG. 2004;111(3):200-6.

15.LEVINE RJ et al. Circulating Angiogenic Factors and the Risk of Preeclampsia. N Engl J Med 2004; 350:672-683

16.ZHOU CC, ZHANG Y, IRANI RA, ZHANG H, MI T, POPEK EJ, HICKS MJ, RAMIN SM, KELLEMS RE, XIA Y. Angiotensin receptor agonistic autoantibodies induce pre-eclampsia in pregnant mice. Nat Med. 2008;14(8):855-62. 
17.BURKE SD, KARUMANCHI SA. Spiral artery remodeling in preeclampsia revisited. Hypertension. 2013;62(6):1013-4.

18.CUCIUREANU DI, STATESCU, C, SASCAU RA, CUCIUREANU T, CONSTANTINESCU VA, HINGANU D, PREDA C, HINGANU MV, TURLIUC MD. Particularities of Using Contrast Agents in Diagnosis of Stroke.Rev Chim (Bucharest), 70, no. 2, 2019, p. 685-688.

19.LYALL F, ROBSON SC, BULMER JN. Spiral artery remodeling and trophoblast invasion in preeclampsia and fetal growth restriction: relationship to clinical outcome. Hypertension. 2013; 62(6):1046-54.

20.SMADI S, POPOVICI I, COJOCARU I, BRAHA S, OCHIUZ L, DORNEANU O. Physico-chemical Characterization, Rheological Behaviour and Evaluation of Antifungal Activity of Propiconazole Nitrate Gels. Mat. Plast., 46, no. 1, 2009, p. 83-90

21.VERLOHREN S, GALINDO A, SCHLEMBACH D, ZEISLER H, HERRAIZ I, MOERTL MG, PAPE J, DUDENHAUSEN JW, DENK B, STEPAN H. An automated method for the determination of the sFlt-1/PIGF ratio in the assessment of preeclampsia. Am J Obstet Gynecol. 2010 Feb;202(2):161.e1-161.e11.

22.HINCHEY J, CHAVES C, APPIGNANI B, BREEN J, PAO L, WANG A, PESSIN MS, LAMY C, MAS JL, CAPLAN LR. A reversible posterior leukoencephalopathy syndrome. N Engl J Med. 1996; 22;334(8):494-500.

23.UMAPATHY A, CHAMLEY LW, JAMES JL. Reconciling the distinct roles of angiogenic/anti-angiogenic factors in the placenta and maternal circulation of normal and pathological pregnancies. Angiogenesis 2019.

24.Hendrix, MLE, Bons JAP, van Haren A et al. Role of sFlt-1 and PlGF in the screening of small-for-gestational age neonates during pregnancy: A systematic review. Ann Clin Biochem 2019; 0(0): 1-5

Manuscript received: 15.01 .2020 